\title{
HISTÓRIAS E MEMÓRIAS DAS MULHERES NA TRAVESSIA A NADO MAR GRANDE - SALVADOR: OUSADIAS NO MAR ABERTO
}

\author{
Lygia Maria dos Santos Bahia \\ Universidade Federal da Bahia, Salvador, Bahia, Brasil \\ Maria Cecília de Paula Silva \\ Universidade Federal da Bahia, Salvador, Bahia, Brasil
}

\begin{abstract}
Resumo
O presente artigo visa refletir sobre memórias e histórias das primeiras participações femininas de natação na Travessia Mar Grande - Salvador, Bahia, Brasil, objetivando dar visibilidade à historia das mulheres em competições de águas abertas no Brasil nos anos 1950 e sua relação com a educação à época. A pesquisa histórica privilegiou a pesquisa documental e a pesquisa oral temática, tendo como instrumentos jornais e entrevistas como fontes primárias. Das considerações, destacamos a participação das mulheres desde as primeiras provas dessa travessia, o que sugere uma perspectiva educacional diferenciada para determinadas mulheres da sociedade baiana ainda na primeira metade do século XX e uma nuance de alteração de posturas e ações.
\end{abstract}

Palavras-chave: História das mulheres. Natação em águas abertas. Educação.

\section{Introdução}

\section{Mergulhando em águas abertas...}

A Rio 2016 é considerada a olimpíada mais feminina da história, superando a de Londres 2012 em número de participações de mulheres nas modalidades esportivas. A participação das mulheres nos Jogos Olímpicos já é tema de estudos históricos, embora ainda não seja suficientemente explorada. No Brasil, encontramos referências sobre as primeiras participações femininas nos esportes em estudos como os de Lenk (1982), Silva (1999), Devide (2004), Goellner (2005), para citar alguns.

Na edição dos Jogos Olímpicos de 2016, as "mulheres representaram 45\% de atletas inscritos para os jogos, totalizando 5.183" (BRASILPOST, 2016), em todas as modalidades esportivas. Podemos considerar este um marco importante a ser destacado. Neste ponto, outro destaque é o caso das Maratonas Aquáticas, que ganharam o status de esporte olímpico em 2016 e, logo na sua estreia, tiveram maior participação de atletas femininos do que masculinos $-51 \%$, como registrado no site oficial do evento (RIO 2016, 2016).

A estreia nos Jogos Olímpicos é recente, mas a competição de natação em águas abertas já tem história. Em se tratando da participação de mulheres na natação em águas abertas no Brasil, Lenk (1982) registra que, em 1925, Anésia Coelho e Alice Possalo fizeram a Travessia da Guanabara, numa distância de aproximadamente $5 \mathrm{~km}$, com saída da Praia da Boa 
Viagem até a Praia das Virtudes. Em São Paulo, o Rio Tietê foi local, no início do século XX, de provas femininas com distâncias de 25m e 50m (LENK, 1982). Devide (2012), ao tratar do pioneirismo da natação competitiva feminina no Brasil, nos fala da participação de Haydée Bueno de Camargo numa prova demonstrativa de 50m, em 25 de março de 1917, na Associação Athletica São Paulo, clube localizado às margens do Rio Tietê.

No estado da Bahia, registramos a participação oficial de mulheres em provas de natação em águas abertas desde 1956, quando Angela Maria Carvalho participa da Prova Baía de Todos os Santos, competição em mar aberto, criada em 1955, que, com o passar do tempo, afirma-se como a Travessia Mar Grande - Salvador. Realizada geralmente no mês de janeiro, completou, em 2016, a 52a edição. A prova ocorre na Baía de Todos os Santos, com um percurso de no mínimo 9.250m, se considerado em linha reta. A saída é na Praia do Duro, distrito de Mar Grande, município de Vera Cruz, Ilha de Itaparica, e a chegada, na praia do Porto da Barra, em Salvador.

Essa travessia em mar aberto teve grande repercussão local, “[...] o interesse em torno da disputa este ano cresceu de maneira tal que passou o futebol a plano secundário, sendo em todos os pontos da cidade o assunto máximo de todas as palestras" (DIARIO DA BAHIA, 15 jan. 1957, p. 6). Era considerada pelos periódicos soteropolitanos como "a mais longa em nosso país e uma das mais importantes do continente" (A TARDE, 10 jan. 1956, p. 5). O Diario de Noticias (24 jan. 1956, p.6) afirmava que pelas "suas características a prova, era a mais importante do país e uma das mais extensas do mundo".

Sobre as primeiras participações de mulheres, nos anos de 1956 e 1957, embora fossem destaque (com grande repercussão na imprensa e na sociedade soteropolitana), elas foram muito reduzidas. É sobre essa participação que tratamos neste estudo, cujo objetivo é refletir sobre os sentidos e significados das primeiras participações femininas de natação na Travessia Mar Grande - Salvador, Bahia, Brasil, a partir das histórias e memórias dessas nadadoras, com a perspectiva de tornar visível um pouco da história das mulheres em competições de águas abertas no Brasil, em meados do século XX, e sua relação com a educação à época.

Optamos por trabalhar com a história oral temática, privilegiando depoimentos e entrevistas, além de outros documentos. Sobre a história oral, Thompson (1992) nos fala que ela pode vir a ser um meio de transformar tanto o conteúdo quanto a finalidade da história, por propiciar uma reconstrução histórica mais realista, o que imprime um compromisso social. Utilizamos como fontes documentais o jornal $A$ Tarde, periódico responsável pela criação e pela organização dessa competição e um de seus patrocinadores, e os jornais Diario de Noticias e Diario da Bahia. Consultamos, igualmente, livros e artigos que falam sobre a história das mulheres, além de sites e publicações de periódicos online.

Foram realizadas entrevistas com a primeira mulher que concluiu a Travessia, a nadadora Marília Barreiros Correia de Melo e registrados depoimentos da mesma. Realizamos, igualmente, entrevista com o professor de Educação Física, técnico de natação e árbitro internacional de Maratonas Aquáticas, Sued Awad. Como dispositivo de pesquisa, relativos à história oral, optamos pela entrevista temática semiestruturada por se referir "a experiências ou processos específicos vividos ou testemunhados pelos entrevistados [...]" (DELGADO, 2006, p. 22). Relatos que oportunizam explorar a oralidade, por falarem livremente sobre o tema e fornecerem fatos, eventos, posicionamentos importantes.

Consideramos a perspectiva apontada por Véron (1980) da análise de conteúdo para sinalizar e refletir sobre a produção dos sentidos. Nesta, se observa e analisa algumas unidades de registro, quando significativas, em um determinado contexto. Outro ponto relevante é a observação e análise das ocorrências sobre o que se está investigando. Neste caso específico, destacamos os sentidos registrados nos jornais à época, por jornalistas designados para cobrirem este evento que liga duas cidades por meio da natação e que, em várias ocasiões, destaca 
a participação das mulheres nesta Travessia, além das marcas deixadas por esta modalidade esportiva nos corpos das atletas pioneiras nesta aventura ao mar.

\section{Mulheres ao mar: a estreia}

A Travessia Mar Grande - Salvador era considerada, na época, pelos periódicos locais, a maior prova brasileira, figurando entre as maiores do mundo. "Como todos sabem a competição Mar Grande - Salvador figura entre as maiores do mundo conforme estudo de um oficial da Base Naval sendo a prova máxima da natação brasileira" (A TARDE, 17 jan. 1956, ano 44, n. 14673, p.5). Segundo esse oficial, denominando Papyrio Brasil, estava "entre as mais extensas do mundo, sendo a principal do país (A TARDE, 21 jan. 1956, p. 2).

Essa competição tem a peculiaridade de partir de uma ilha, atravessar uma baía e chegar ao continente. Sobre esse percurso, Sued Awad" comenta ser deslumbrante "você estar na praia da ilha, olhar o continente e dizer assim: eu vou para o continente". Sobre a importância da competição, ele sugere que:

(se) as Maratonas Aquáticas estão hoje onde estão agradeça a Mar Grande - Salvador. Se temos, hoje, dois atletas nas olimpíadas, se temos dois árbitros internacionais, se temos o circuito mais forte do Brasil é muito pela Travessia Mar Grande.

Ao refletirmos sobre esta possível contribuição para a história e a importância da travessia para o que assistimos hoje, questionamos se ela, de fato, existiu. No cenário local, à época, a travessia foi de grande relevância esportiva, como é evidenciado nos periódicos de grande circulação.

A participação feminina na Travessia Mar Grande - Salvador iniciou-se na sua $2^{\mathrm{a}}$ edição, em 22 de janeiro de 1956, com Angela Maria Carvalho Nascimento, nadadora de 18 anos, do Clube São Salvador. Sob o título "Uma mulher na prova de natação Mar Grande Salvador", o jornal $A$ Tarde anunciava a inscrição da nadadora Angela Maria. Na matéria, a atleta era enaltecida pela mocidade e pela beleza (A TARDE, 11 jan. 1956, p. 2).

Observamos, ao longo das referências feitas à nadadora, expressões ressaltando qualidades que representam a mulher do período, ou seja, a graça, a elegância, a beleza. Nessa época, características atribuídas à mulher como feminilidade, maternidade, doçura, delicadeza, dentre outras, são definidas como os ideais para o sexo feminino.

Ao considerarmos uma competição em mar aberto, significa adentrarmos em uma dimensão mais específica, por exigir das atletas valores bastante diferenciados do padrão social à época, quais sejam: coragem, determinação, força, virilidade, entre outros. A partir de então, a participação feminina tem revelado uma história de determinação, coragem e bravura das mulheres, apesar de se manter o estigma do "belo sexo" nas recorrentes expressões do jornal $A$ Tarde da época ao se referir às nadadoras.

Perrot $(2015$, p.21) afirma que a presença feminina "é frequentemente apagada, seus vestígios, desfeitos, seus arquivos destruídos". Entretanto, a história da Travessia Mar Grande - Salvador destaca a participação das mulheres nesse momento histórico, o que, de certa forma, contraria, em parte, essa afirmação de Perrot, pois ela entende que a história das mulheres sofre modificações profundas ao sair do espaço doméstico, privado, para o espaço público.

Nos anos 1950, segundo Tomé (2013), havia uma preocupação na educação de mulheres a respeito das relações conjugais. Os manuais de instrução feminina tinham um papel importante na educação e na formação da sua identidade. Neles, cuidados com corpo, feminili-

\footnotetext{
${ }^{1}$ Professor de Educação Física brasileiro, treinador de natação em Salvador, árbitro internacional de Maratonas Aquáticas e integrante da equipe de arbitragem desta modalidade na Rio 2016.
} 
dade, valores, hábitos, comportamentos são 'ensinados', visando conformar a mulher a um papel social determinado - o de mãe, esposa e dona de casa -e, desse modo, o casamento era o seu destino.

Referindo-se ao mesmo período, Arend (2013) diz que a leitura de romances denominados "água com açúcar" e de revistas femininas eram os passatempos preferidos das meninas nas escolas. Essas publicações literárias periódicas e as informações obtidas nas escolas propalavam regras de etiqueta e noções de elegância, com o intuito de servir às meninas para, na vida adulta, colocarem-nas em prática.

Apesar do avanço da participação feminina em atividades físico-esportivas no início do século XX, a presença da mulher no cenário esportivo nos anos 1950 ainda era reduzida, muito em função de seu papel social se restringir ao ambiente doméstico e a todas as tarefas que este determinava, de maneira predominante. Este cenário era reproduzido nos periódicos, como atesta Mourão (1996, p. 62): "o cuidado com a beleza e a leveza estão associados ao encantamento feminino e onipresentes no discurso jornalístico e nos valores da sociedade da época".

A participação da nadadora Angela constituía uma atração para a segunda Mar Grande - Salvador por ser "a primeira moça a tentar tal façanha. Possuindo muita fibra e sobretudo classe” (A TARDE, 12 jan. 1956, p. 2). Observa-se que, neste discurso midiático, expressões como classe, beleza, elegância são recorrentes. Isso denota valores sociais relativos à mulher. Neste artigo, há também alusão a valores atléticos da nadadora (muita fibra), o que significa uma singela modificação.

Nesta competição, não havia sido inscrita nenhuma outra mulher além de Angela Nascimento, que foi, por isso, considerada uma atração singular. No dia anterior da prova, o jornal exaltava a sua participação:

[...] a coragem e o desprendimento desta moça de 18 anos, merecem sem dúvida alguma, as atenções do público esportivo da Bahia, não só pela sua condição de mulher como também pelo fato que ela nadará todo o "percurso de prova em nado de costas", reconhecidamente, em estilo de difícil aplicação em mar batido (A TARDE, 20 jan. 1956, p. 5).

Nota-se na matéria um discurso em que o jornalista nos apresenta uma nova realidade: a da mulher que sai do ambiente doméstico e avança para novas conquistas sociais. Desse modo, ao mesmo tempo em que se reporta à coragem da nadadora, característica tipicamente masculina, fala do seu desprendimento, da sua "condição de mulher", ressaltando no discurso a palavra desprendimento, que, segundo o Dicionário Infopédia (2003-2017), significa "ato de desprender-ser, desapego, abnegação" - características estas valorizadas e incentivadas para o sexo feminino.

Além disso, afirma que "existe" uma "condição para a mulher". Referências à "condição feminina" ou à "natureza da mulher" são recorrentes nos escritos da época. Tomé (2013) aponta que a educação feminina no Brasil conformou a mulher para atividades e comportamentos como a cooperação com o outro sexo, a obediência, o altruísmo, a docilidade, dentre outros. Como "condição de mulher", subentende-se aquela estabelecida historicamente, qual seja: incapacidade, inaptidão, fragilidade, inferioridade, subalternidade, dentre outras.

Mourão (2000) comenta sobre os argumentos para a negação da participação de mulheres em atividades físicas e esportivas nas primeiras décadas do século XX. Havia artigos científicos que defendiam a inaptidão feminina para a atividade física e o esporte, desaconselhando todos os que exigissem força muscular. A autora aponta o Decreto-lei 3.199, de 1941 (vigorou até 1975), impedindo práticas desportivas que não fossem compatíveis com as condições da natureza feminina. 
Na segunda edição da travessia, estabeleceu-se uma prova eliminatória dez dias antes da competição, só para os atletas locais. Ficaram isentos da prova os cinco classificados na primeira Travessia Mar Grande - Salvador, atletas de outros estados e a única mulher inscrita: Angela Nascimento. Detectamos um "cuidado" especial com a única nadadora que, possivelmente por ser mulher, gozou dessa prerrogativa. Sobre esse "cuidado", Perrot $(2015$, p. 42) nos diz que: "A precaução é um ingrediente antigo na educação das mulheres". Nossa sugestão inicial se confirma na edição seguinte que, apesar de ter quatro participações femininas na prova, continuou isentando-as da prova eliminatória.

Diferente de hoje em dia, em que os nadadores e nadadoras partem da areia, àquela época os atletas e a atleta ocuparam cada um a sua embarcação e se dirigiram até o local onde seria dada a partida junto ao farolete na linha dos arrecifes, defronte de Mar Grande. Às 8h e 14min do dia 22 de janeiro de 1956, foi dado o tiro de partida. Ao sinal da pistola, saltaram para a água rumo ao continente. Havia, porém,

uma curiosa balsa montada em flutuadores, onde senhoras e senhoritas, acomodadas em confortáveis cadeiras e se preparavam para acompanhar a Prova. [...] Pintada de amarelo, ostentava uma inscrição - "torcida de Angela". Vários barcos a acompanhavam [...] num deles seu pai e preparador. [...] Angela deslocava-se na água nadando de costas. Não tinha pressa, frequentemente respondia com acenos e sorrisos as demonstrações dos "fans" (A TARDE, 23 jan. 1956, p. 2).

Importante analisar a postura da nadadora e o comportamento da população que lhe assistia. Percebemos nestas notícias do A Tarde que a participação de Angela provocou uma expectativa muito grande, além da curiosidade pela participação de uma mulher na travessia.

Em certo sentido, esta participação contrariava o modelo feminino preconizado nos anos 1950 - o de formar a mulher para o casamento, para a maternidade e para os cuidados da família; papéis considerados 'naturais' para o sexo feminino. Pinsky (2013, p. 488) afirma que "nos anos 1950, ainda que com pinceladas de modernidade, o ideal da 'boa esposa' seguia como grande farol". Nessa perspectiva, características como a coragem e o espírito aventureiro, necessários para uma competição dessa natureza, eram estranhos à "condição feminina", pois, como atesta Perrot (2015, p. 42), "o risco, sob todas as formas, é inerente à cultura da virilidade".

Destarte toda a expectativa quanto a esta primeira participação de uma mulher na travessia, Angela não conseguiu entrar no Porto da Barra, devido às más condições da maré, abandonando a prova ao final. Após nadar $4 \mathrm{~h}$ e $33 \mathrm{~min}$, foi recolhida ao barco, apesar dos insistentes pedidos da nadadora para permanecer na prova. Seu pioneirismo nesta prova pode ter aberto caminho para outras mulheres realizarem o desafio da Travessia Mar Grande - Salvador e, quiçá, apontar outros paradigmas sobre o papel social e possibilidades de outra educação para as mulheres.

O reconhecimento desta participação foi ressaltado, em homenagem especial, na entrega dos prêmios. Angela ganhou uma taça oferecida pela Federação Bahiana de Natação (FBN), além de prêmios ofertados por empresas comerciais. A corajosa moça que realizou a travessia recebeu os aplausos e a simpatia dos presentes (A TARDE, 6 fev. 1956, p. 2). Desta forma, encerrou-se a segunda Prova da Baía de Todos os Santos.

\section{A travessia é completada por uma mulher - uma ousadia para a época}


A terceira Travessia Mar Grande - Salvador é assim referida pelo A Tarde (8 jan. 1957, p. 7): "o belo sexo estará prestigiando de maneira decisiva a grande prova de natação denominada "Baía de Todos os Santos"”. A imprensa escrita continua a utilizar a expressão "belo sexo" quando se refere à participação feminina, num reforço à representação social da mulher nos anos 1950. Esta reportagem informava a participação das inscritas: Marlene Gomes Nascimento, "a índia de Mar Grande" (sem clube); Angela Maria (Esporte Clube Bahia); Marília Barreiros (Esporte Clube Vitória), considerada uma das maiores estilistas do Norte do país. Nesta edição, aguardava-se também a carioca Isa Teixeira, que não compareceu, e a paulista Egle Blanco (Internacional de Regatas de Santos).

Às 6h25min, "o tenente da marinha [...] deu o tiro de largada para as moças que se dispuseram a arriscada travessia" (A TARDE, 21 jan. 1957, p. 3). Pelos registros, Marília e Egle tomaram a direção do Monte Serrat:

Foi um duelo espetacular das duas formosas e jovens atletas, até a meia travessia, quando a bahiana conseguiu tomar a dianteira até o funil de chegada na praia da Barra, quando foi recebida com estrepitosas aclamações pelo povo que ali se aglomerava nas balaustradas e pelos banhistas que acorreram a saudá-la, tornando até difícil a penetração no funil. Foi um dos momentos emocionantes da grande prova (A TARDE, 21 jan. 1957, p. 3).

A escrita da época repete o padrão de narrativa de outras publicações do jornal, enaltecendo a estética feminina e caracterizando uma representação social hegemônica para a mulher. O destaque da "formosura" das nadadoras pode ser interpretado como o desejo de garantir a elas a "condição de mulher" tão assinalada no período. O relato da recepção da nadadora pelos presentes e a afirmação da chegada de uma mulher são considerados como um dos momentos mais emocionantes da prova.

Sobre a expressão "o belo sexo", incansavelmente utilizada pelo discurso jornalístico do A Tarde, pode ser analisado como um marco de época. Isto porque, nos dias atuais, expressões como essa "perdem sentido, enquanto que valores masculinos sofrem também profunda transformação. Tudo muda se as qualidades físicas não mais são delimitadas. Tudo muda se a força não mais é apropriada por um sexo, deixando no espelho a estética ou a fraqueza igualmente não apropriadas" (VIGARELLO, 2013, p. 293).

As nadadoras Marília, Angela e Egle foram levadas pela maré para o Farol da Barra. Marília nadou próxima às pedras, contra a maré, e conseguiu chegar ao Porto, sendo a única mulher a cruzar o funil ${ }^{2}$, após a chegada do quinto homem. As outras chegaram a Salvador em um outro ponto, devido à forte maré. Na classificação feminina, Marília aparece em $1^{\circ}$, Egle em $2^{\circ}$ e Angela em $3^{\circ}$ lugar. Marlene desistiu da competição, faltando um pouco mais de uma milha (A TARDE, 21 jan. 1957, p. 3).

Este feito realizado por Marília, nascida em 13 de março de 1938, é, em parte, resultado de uma história iniciada aos 6 anos, quando aprendeu a nadar no mar da Península Itapagipana, e que continuou na escola, com seu ingresso no antigo Instituto Normal da Bahia ${ }^{3}$, em 1948: "ao me matricular no Instituto Normal me perguntaram: Aqui nós temos ginástica e natação, você quer o quê? Vim de Itapagipe, acostumada ali. Disse: Natação! Aí, já entrei direto pra natação, o técnico era Aurino Almeida", narra Marília.

\footnotetext{
${ }^{2}$ A colocação do "moderno funil" ficou a cargo do Iate Clube da Bahia. Ao término do funil, foi instalado um flutuador, onde ficava o juiz de chegada, recebendo os nadadores que completavam a prova. O flutuador facilitava ao público identificar o vencedor e acompanhar os outros atletas que concluíam o percurso.

${ }^{3}$ Primeira escola normal do estado, fundada em 14 de abril de 1836, através da Lei Provincial no 37 . Em 1968, passou a se chamar Instituto Central de Educação Isaías Alves (ICEIA), hoje transformado no Centro Estadual de Educação Profissional em Apoio Educacional e Tecnologia da Informação Isaías Alves (CEEP).
} 
Sobre a Travessia Mar Grande - Salvador, Marília comenta: "a primeira eu assisti no rádio, que foi o Liberato aceitando o desafio com outro cara. A rádio Cruzeiro transmitiu, aí eu disse: para o ano, eu vou fazer". Interessante destacar o papel que a mídia ocupou neste desafio. Não somente a mídia escrita, como também a rádio responsável, no caso em questão, por tornar público este evento e despertar nas pessoas o desejo em participar dele. Entretanto, em 1956, a nadadora ainda não conseguiu o desejado, pois não tinha a idade mínima exigida para participar deste evento, 18 anos. Sua vontade só se realizou em 1957, sendo repetida em varias ocasiões (com 18, 19, 20, 50, 51 e 60 anos). E ela deseja participar aos 80 anos. "A idade me motiva", esclarece Marília.

Marília rememora: "é muito significativo, realização total. Foi muito sacrifício, esforço para treinar". O conteúdo de suas narrativas sugere-nos uma outra educação feminina. Ao possibilitar algumas opções esportivas, no caso, a natação, modalidade permitida ao sexo feminino por não alterar a configuração corporal e auxiliar a função reprodutiva, abriu brechas para a ousadia de enfrentar o mar aberto, as correntezas da Baía de Todos os Santos. E isso exigia muito treino, muita força física, o que fugia aos padrões indicados ao corpo e às atividades esportivas para as mulheres pela educação feminina da época.

Assim, a participação na Travessia Mar Grande - Salvador anuncia uma modificação no comportamento esperado para as mulheres nos anos 1950. Pinsky (2015) comenta que, no Brasil, mesmo após a Segunda Guerra Mundial, quando as condições de vida nas cidades diminuíram muitas as distâncias entre os homens e as mulheres, as demarcações entre os papéis femininos e masculinos continuavam nítidas.

De acordo com Almeida (1998), o final do regime ditatorial no Brasil e a retomada dos ideais democráticos coincidiram com o término da Segunda Guerra Mundial, contribuindo para uma modificação da representação social da educação feminina e do papel da mulher na sociedade que se delineava. Entretanto, apesar de algum avanço da participação da mulher no ambiente público, o Brasil foi influenciado por campanhas estrangeiras que pregavam a volta das mulheres para o lar e aos valores tradicionais da época.

Nos anos 1950, havia uma expectativa social para a mulher:

Ser mãe, esposa e dona de casa era considerado o destino natural das mulheres. Na ideologia dos Anos Dourados, maternidade, casamento e dedicação ao lar faziam parte da essência feminina; sem história, sem possibilidades de contestação (PINSKY, 2015, p. 609).

Treinar, ser resistente, determinada, corajosa eram características eminentemente masculinas. Nos anos 1950, atributos como "[...] a iniciativa, a participação no mercado de trabalho, a força e o espírito de aventura definiriam a masculinidade" (PINSKY, 2015, p. 609). Marília, Angela, Marlene e Egle se inseriram em espaços que não eram tipicamente femininos, o que contribuiu para a ruptura de preconceitos, de padrões secularmente estabelecidos. Podem, inclusive, ter sido inspirações para outras mulheres de sua época para ousar em outras práticas esportivas e, quiçá, outras conformações sociais. A determinação e a garra de mulheres como elas nos informam outros sonhos. Informam mais: que precisamos enfrentar obstáculos para superá-los, conforme nos narra Marília, ao enfrentar a correnteza em 1957: "devido à correnteza, cheguei no Porto mas não consegui entrar. Orientada pelo barqueiro, precisei ir para o Farol da Barra e de lá retornei nadando 'colada' nas pedras. Não podia colocar os pés no chão porque era desclassificada. Me disseram 'só tem você nadando', aí me deu uma vontade maior de chegar".

Sobre a participação das mulheres na Travessia, o jornal A Tarde destacava pontos singulares. Pela atuação de Angela na segunda edição da competição, o jornal a elogiava por dar "[...] provas da bravura e da coragem da mulher bahiana [...] e que [...] sozinha, como legítima representante do belo sexo, [...] chamou a si quase tôda a expectativa em torno daquela 
maratona. Não conseguiu vencer o percurso, porém faltou muito pouco". Sobre a terceira edição, afirmou a importância da participação de Marília, considerando-a uma grande atração: "iria abrilhantar a prova que naquele ano teria o caráter interestadual. E conclui, afirmando: "Ademais é muito corajosa daí acreditarmos na bela representante" (A TARDE, 8 jan. 1957, p. 7)

Em uma aproximação relativa ao espaço reservado no A Tarde para o noticiário esportivo masculino e feminino, constatamos a predominância do primeiro e a pouca participação/valorização da participação esportiva feminina. O discurso jornalístico reitera a concepção de gênero do período, apesar de admitir a possibilidade de outros valores culturalmente tratados como características do homem e que estas jovens necessitavam ter para atingir o seu objetivo - atravessar a nado a Baía de Todos os Santos.

A participação feminina no esporte baiano seguia um percurso semelhante ao que acontecia em outros estados do país. Progressivamente as mulheres saíam da condição de espectadoras para a de praticantes, e as diversas mídias influenciavam bastante este movimento. Vigarello (2013, p. 294) argumenta que meios de comunicação como as revistas, por exemplo, são inventados "privilegiando a beleza e o cuidado. Códigos de avaliação se transformam, deslocando valores e objetos". Podemos, assim, considerar que, no discurso do $A$ Tarde sobre a participação das mulheres na Travessia Mar Grande - Salvador, o enredo do belo sexo vai sendo, aos poucos, deslocado, referindo-se menos à elegância e ao contorno corporal e mais às características de coragem, bravura e determinação.

\section{Considerações finais}

O presente artigo pretendeu refletir sobre a ousadia das primeiras participações femininas de natação na Travessia Mar Grande - Salvador, Bahia, Brasil, objetivando dar visibilidade à história das mulheres em competições de águas abertas no Brasil, em meados do século XX, e sua relação com a educação à época, por meio da história documental impressa e oral temática.

A segunda Travessia Mar Grande - Salvador representa, na Bahia, um importante marco da participação das mulheres em provas em mar aberto, quiçá, no Brasil. A nadadora Angela Maria de Carvalho teve o mérito de ser a primeira mulher a participar desta prova, atravessar a Baía de Todos os Santos e lutar por várias horas contra a correnteza. Apesar de não ter finalizado a competição, ela é o ponto de partida da história feminina da Mar Grande Salvador. Na terceira edição dessa travessia, Marília realizou o feito de cruzar o funil de chegada, e Angela e Egle finalizaram a prova, mesmo não alcançando o ponto de chegada, a praia do Porto da Barra.

Uma mulher pretender atravessar a nado a Baía de Todos os Santos contrariava o modelo feminino preconizado na época - formar a mulher para o casamento, para a maternidade e para os cuidados da família, papéis sociais considerados como naturais para o sexo feminino. Nessa perspectiva, características como a coragem e o espírito aventureiro, necessários para uma competição dessa natureza, eram estranhos à "condição feminina". Aliás, estas referências à "condição feminina" ou à "natureza da mulher" são recorrentes nos escritos da época, apontando como representação social feminina prevalecente a fragilidade, a inferioridade, a subalternidade, dentre outras.

Consideramos que se apropriar dessa história de mulheres e dar-lhe visibilidade significa retirá-las da invisibilidade, do silêncio, da coadjuvação para o protagonismo de sua própria história. Significa também perseguir alguns dos sentidos gerados ao participar de provas de natação em mar aberto, num momento em que o lugar hegemônico das mulheres ainda era o doméstico. 
Mulheres como Marília, Angela, Marlene, Egle deixaram um legado quando pensamos no pioneirismo das mulheres em provas de longa distância em mar aberto. Elas romperam os padrões, as normas e os comportamentos esperados para as mulheres. Este novo caminho, para além-mar, pode ter possibilitado outras travessias.

Nesta esteira, acreditamos que a terceira Travessia Mar Grande - Salvador revela uma importância para a natação em águas abertas na Bahia. Nesta edição, pela primeira vez uma mulher concluiu o percurso. Que venham outros e mais desafios e que possamos ter mais mulheres rompendo normas e padrões, sonhando e realizando desejos, vivendo a vida como sujeitos de suas histórias, apesar das barreiras, marés e correntes desfavoráveis, que, por vezes, nos puxam para outros percursos.

\title{
STORIES AND MEMORIES OF WOMEN AT THE CROSSING BY SWIMMING MAR GRANDE -SALVADOR: DARINGS IN OPEN SEAS
}

\begin{abstract}
The article aims at reflecting on stories and memories of the first female swimmer's participations in the Mar Grande - Salvador, BA Crossing, with the objective of giving visibility to the stories of women in open sea competitions in Brazil in the fifties and its relation with the education at that time. Historic research favoring documental and oral thematic research. Contemporary newspapers and interviews where our primary sources. Key considerations were the participation of women since the first competitions of this Crossing, which suggests a differentiated educational perspective for certain women of Bahia's society still in the first half of the $20^{\text {th }}$ century and a nuanced change in postures and actions following the daringness of engaging in the open sea Crossing.
\end{abstract}

Key words: Women's stories. Open sea swimming. Female education

\section{HISTORIAS Y MEMORIAS DE LAS MUJERES EN LA TRAVESIA A NADO MAR GRANDE - SALVADOR: AUDACIA EN EL MAR ABIERTO}

\section{Resumen}

Objetiva reflexionar sobre historias y memorias de las primeras participaciones femeninas de natación en la Travesia Mar Grande - Salvador/BA, a dar visibilidad a la historia de las mujeres en competencias de aguas abiertas en Brasil en 1950 y su relación con la educación. Investigación histórica que privilegia la documental y oral temática. Periódicos de la época y entrevistas fueron nuestras fuentes primarias. De las consideraciones, la participación de las mujeres desde las primeras pruebas de esa Travesia, sugiere una perspectiva educacional diferenciada para determinadas mujeres de la sociedad bahiana aún en la primera mitad del siglo XX y un matiz del cambio de posturas y acciones a partir de la audacia femenina de tirarse al agua en la Travesia a nado en mar aberto.

Palabras claves: Historia de las mujeres. Natación en aguas abiertas. Educación femenina.

\section{Referências}

ALMEIDA, J. S. de. Mulher e educação: a paixão pelo possível. São Paulo: Editora UNESP, 1998. (Prismas). 
AREND, S. F. Trabalho, escola e lazer. In: PINSKY, C. B. ; PEDRO, J. M. (Org). Nova história das mulheres no Brasil. São Paulo: Contexto, 2013. p. 65-83.

A TARDE. Marcada para domingo a eliminatória dos nadadores. Salvador, 10 jan. 1956, ano 44 , n. 14.667 , p. 5.

. Uma mulher na prova de natação. Mar Grande - Salvador. Salvador, 11 jan. 1956, ano 44 , n. 14.668 , p. 2.

A jovem Angela Maria será uma das grandes atrações. Salvador, 12 jan. 1956, ano 44, n. 14.669 , p. 2.

n. 14.673 , p. 5 .

. Começará amanhã o exame médico dos nadadores. Salvador, 17 jan. 1956, ano 44, . Angela uma atração singular. Salvador, 20 jan. 1956, ano 44, n. 14.676, p. 5.

. Manhã de emoção e de festa. Salvador, 21 jan. 1956, ano 44, n. 14.677, p. 2.

. Nadadores atravessaram a baía Salvador, 23 jan. 1956, ano 44, n. 14.678, p. 2.

- Apoteose de aplausos coroando a prova esportiva d'A TARDE. Salvador, 6 fev. 1956, ano 44, n. 14.690, p. 2.

A campeoníssima participará da Travessia. Salvador, 8 jan. 1957, ano 45, n. 14.967, p. 7

BENJAMIN, W. Charles Baudelaire, um lírico no auge do capitalismo. São Paulo: Brasiliense, 2000. (Obras escolhidas, v. 3).

BRASIL. Maratonas Aquáticas nos Jogos Olímpicos. 2016. Disponível em: < http://brasil.elpais.com/tag/c/6a9097e00a8d3d92e124a02eadb4a0fb>. Acesso em: 1 nov.2016.

BRASIL 2016. Maratonas Aquáticas. 2016. Disponível em: s http://www.brasil2016.gov.br/pt-br/olimpiadas/modalidades/maratonas-aquaticas $>$. Acesso em: 1 nov. 2016.

BRASILPOST. Com mais de 5 mil atletas, Rio 2016 é a Olimpíada mais feminina da história. 2016. Disponível em: <http://www.brasilpost.com.br/2016/08/01/mulheres-na-rio2016_n_11297894.html >. Acesso em: 14 out. 2016.

DELGADO, L. de A. N. História oral: memória, tempo e identidades. Belo Horizonte: Autêntica, 2006.

DEVIDE, F. P. História das mulheres na natação brasileira no século XX: das adequações às resistências sociais. São Paulo: Hucitec, 2012.

DEVIDE, F. P. A natação como elemento da cultura física feminina no início do século XX: construindo corpos saudáveis, belos e graciosos. Revista Movimento, v.10, n.2, p. 125-144, mai./ago., 2004. 
DIARIO DA BAHIA. Travessia Mar Grande-Salvador. Salvador, 15 jan. 1957, ano 101, n. 308, p. 6

DIARIO DE NOTICIAS. Travessia Mar Grande -Salvador. Salvador, 24 jan. 1956, ano LXXX, n.16.419, p.6.

DICIONÁRIO INFOPÉDIA. Língua Portuguesa com Acordo Ortográfico. Desprendimento. Porto: Porto Editora: 2003-2017. Disponível em: <https: //www.infopedia.pt/dicionarios/lingua-portuguesa/desprendimento>. Acesso em: 15 jan. 2017.

GOELLNER, S. V. Mulher e esporte no Brasil: entre incentivos e interdições elas fazem história. Revista Pensar a Prática, v.8, n.1, p. 85-100, jan./jun., 2005.

LENK, M. Braçadas e abraços. Rio de Janeiro: Grupo Atlântica Boa Vista, 1982.

MOURÃO, L. A imagem da mulher esportista nos Jogos da Primavera dos anos 50. In: VORTRE, S. (Coord.). A representação social da mulher na Educação Física e no esporte. Rio de Janeiro: Editora Central da Universidade Gama Filho. 1996.

Representação social da mulher brasileira nas atividades fisico-desportivas: da segregação à democratização. Movimento, ano VII. n. 13, 2000/2. Disponível em:

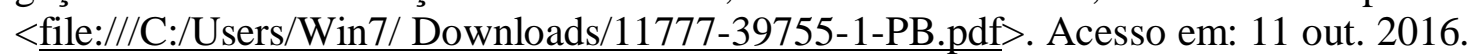

PERROT, M. Minha história das mulheres. 2 ed. São Paulo: Contexto, 2015.

PINSKY, C. B. Mulheres dos Anos Dourados. In: PRIORE, M. D. (Org.). História das mulheres no Brasil. 10 ed. São Paulo: Contexto, 2015. p. 607-639.

A era dos modelos rígidos. In: PINSKY, C. B. ; PEDRO, J. M. (Org.). Nova história das mulheres no Brasil. São Paulo: Contexto, 2013. p. 469-512.

RIO 2016. Jogos Olímpicos. Maratonas Aquáticas. 2016. Disponível em: <https://www.rio2016.com/maratonas-aquaticas >. Acesso em: 11 ago. 2016.

SILVA, M. C. de P. O esporte e a formação da mulher no início do século XX: significados históricos no espaço escolar. In: OLIVEIRA, V. M. de (Org.). História oral aplicada à Educação Física brasileira. Rio de Janeiro: Editoria Central da Universidade Gama Filho, 1998.

, Mulher, Jogos Olímpicos e memória nacional: o caso de Piedade Coutinho. In: TAVARES, O.; DA COSTA, L.P. (Ed.). Estudos olímpicos. Rio de Janeiro: Editora Gama Filho, 1999. p.140-153.

THOMPSON, P. A voz do passado: história oral. São Paulo: Editora Paz e Terra S/A, 1992.

TOMÉ, D. C. Modas e modos domésticos: os manuais de instrução femininos e a educação da mulher - décadas de 1950 e 1960. 2013. 145 f. Dissertação (Mestrado) - Universidade Estadual de Maringá, Maringá, 2013. 
VERÓN, E. A produção de sentidos. São Paulo: Cultrix: Editora da Universidade de São Paulo, 1980.

VIGARELlO, G. Virilidades esportivas. In: CORBIN, A. ; COURTINE, J. J. ; VIGARELLO, G. (Org.). História da virilidade: a virilidade em crise? Séculos XX-XXI. Petrópolis, RJ: Vozes, 2013. p. 269- 301.

Recebido em: 04/02/2017

Revisado em: 07/11/2017

Aprovado em: 29/12/2017

Endereço para correspondência:

lygia.bahia@hotmail.com

Lygia Maria dos Santos Bahia

Universidade Federal da Bahia

Rua Augusto Viana, s/n, Palácio da Reitoria

Canela

40110-909 - Salvador, BA - Brasil 